\title{
The course of traumatic pancreatitis in a patient with pancreas divisum: a case report
} Evangelia G Chryssou*1, Panos Prassopoulos², John Mouzas³, Thomas G Maris ${ }^{1}$ and Nicholas Gourtsoyiannis ${ }^{1}$

\author{
Address: ${ }^{1}$ Department of Radiology, University Hospital of Heraklion, 71110 Stavrakia, Voutes, Greece, ${ }^{2}$ Department of Radiology, University \\ Hospital of Thrace, Greece and ${ }^{3}$ Department of Gastroenterology, University Hospital of Heraklion, Greece \\ Email: Evangelia G Chryssou* - gellych@hotmail.com; Panos Prassopoulos - pprasopo@med.duth.gr; John Mouzas - mouzas@med.uoc.gr; \\ Thomas G Maris - tmaris@med.uoc.gr; Nicholas Gourtsoyiannis - gournick@med.uoc.gr \\ * Corresponding author
}

Published: 14 March 2003

BMC Gastroenterology 2003, 3:4

This article is available from: http://www.biomedcentral.com/I47I-230X/3/4

(c) 2003 Chryssou et al; licensee BioMed Central Ltd. This is an Open Access article: verbatim copying and redistribution of this article are permitted in all media for any purpose, provided this notice is preserved along with the article's original URL.
Received: 16 September 2002

Accepted: 14 March 2003

\begin{abstract}
Background: The peculiar anatomy of pancreatic ducts in pancreas divisum (PD) may interfere with the development of acute chronic pancreatitis. In the presented case, PD influenced the evolution of lesions after pancreatic trauma.

Case presentation: A 38 years old patient refferred to our hospital with recurrent episodes of mild pancreatitis during the last two years. The first episode occurred four months after blunt abdominal trauma. Endoscopic Retrograde Cholangiopancreatography, Magnetic Resonance Imaging of upper abdomen and Magnetic Resonance Cholangiopancreatography disclosed pancreas divisum, changes consistent with chronic pancreatitis in the dorsal pancreatic duct, atrophy in the body and tail of the pancreas and a pseudocyst in the pancreatic head, that was drained endoscopically.
\end{abstract}

Conclusion: Pancreas Divisum may interfere with the evolution of posttraumatic changes in the pancreas after blunt abdominal trauma.

\section{Background}

Pancreas divisum (PD) is the most common congenital anatomic variant of the pancreas. It has been associated with the pathogenesis of acute pancreatitis. PD may also have a role in the development of chronic pancreatitis $[1,13,15]$. In the present report PD has interfered with the evolution of chronic pancreatitis after blunt abdominal trauma.

\section{Case presentation}

A 38 years old male was admitted to hospital with an acute episode of mild abdominal pain with raised levels of serum and urine amylase. The calcium level was within normal limits $(8.9 \mathrm{mg} / \mathrm{dl})$. He had a history of 8 episodes of mild acute pancreatitis during the last 5 years, that were introduced four months after severe blunt abdominal trauma. An ultrasonographic examination, disclosed a cystic lesion at the head of the pancreas. Consequently, the patient was referred for endoscopic retrograde cholangiopancreatography (ERCP). Cannulation of the major papilla revealed a short pancreatic duct branching off regularly, without continuation along the body and tail of the pancreas (fig. 1), suggesting a pancreas divisum. The minor papilla could not be cannulated and thus the dorsal duct was not depicted. The patient underwent Magnetic Resonance Imaging (MRI) of upper abdomen and Magnetic Resonance Cholangiopancreatography (MRCP). MRI demonstrated significant atrophy of the body and tail 




Figure I

Title: ERCP Cannulation of the major papilla and injection of contrast medium results in opacification of a short ventral pancreatic duct and its secondary branches. The dorsal pancreatic duct is not depicted and there is no apparent continuation of the ventral duct along the body and tail of the pancreas.

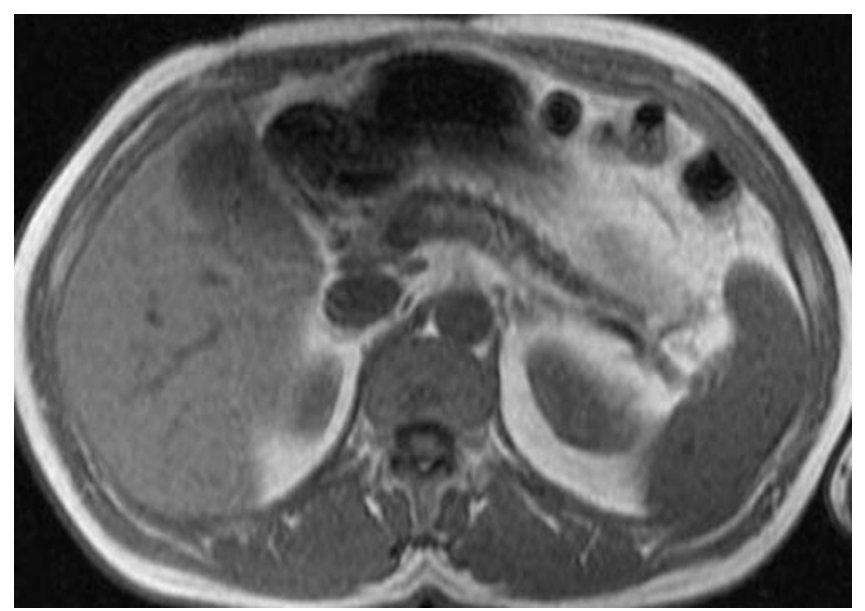

Figure 2

Title: Spoiled gradient echo fat suppressed TI-weighted sequence Axial section at the level of the pancreas, demonstrating significant atrophy of the pancreatic body and tail.

of the pancreas (fig. 2). A small, clearly demarcated cystic lesion was demonstrated in the pancreatic head, in close proximity to the duodenal bulb (fig. 3 ). MRCP revealed a dilated and irregularly beaded dorsal pancreatic duct with

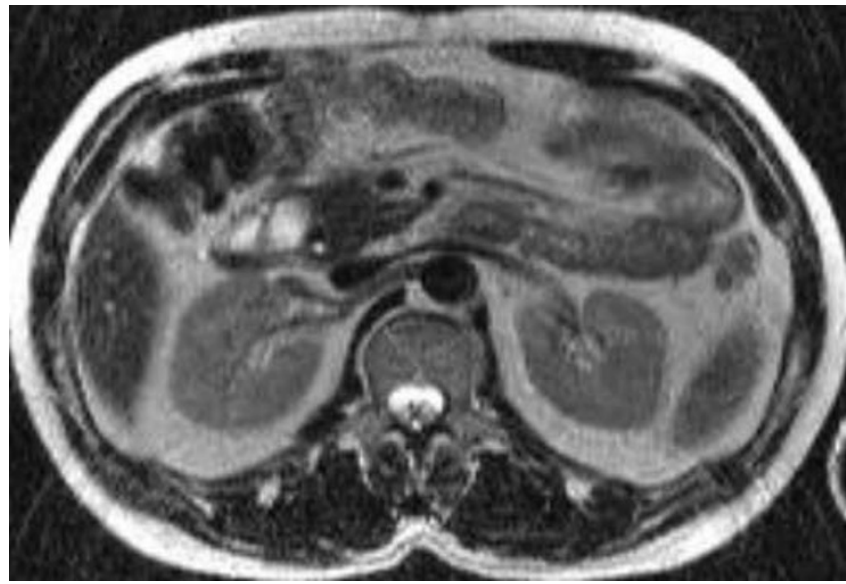

Figure 3

Title: T2-weighted spin echo, axial image. A sharply marginated round lesion $2,5 \mathrm{~cm}$ in diameter, with high signal intensity, consistent with a pseudocyst in the pancreatic head.

side branch ectasia in the body and tail of the pancreas (fig. 4). A short stenotic segment of the duct was demonstrated at the pancreatic neck. The cystic lesion in the pancreatic head was in continuation with this stenotic segment of the pancreatic duct. The duct was shown draining in the duodenum $1-2 \mathrm{~cm}$ superiorly to the draining point of the common bile duct (CBD). The CBD drained in conjunction with the short ventral pancreatic duct at the major papilla. Diagnosis based on ERCP and MRCP findings was pancreatic ductal stenosis, pseudocyst and chronic pancreatitis of the portion drained by the dorsal duct in a pancreas divisum. Internal drainage of the cyst was decided. An upper gastrointestinal endoscopy was performed and a cutting was undertaken by means of a needle knife at the point of a major bulging in the duodenal bulb. A 10 French $5 \mathrm{~cm}$ long pig-tail stent was introduced, thus securing the internal drainage of the cyst. Biochemical tests of cystic fluid were consistent with a pseudocyst. The pig-tail stent was extracted after one month. Following the drainage of the pseudocyst, the patient experienced complete remission of the episodes of recurrent pancreatitis for a two years period follow-up, but he is still, infrequently, complaining of mild upper abdominal pain. Imaging evaluation during follow-up confirmed elimination of the pseudocyst, but the patient is still under clinical follow-up.

The association of PD with chronic pancreatitis limited to the dorsal duct has been previously described in 16 patients on ERCP [1] and in 2 patients on MRCP [3,5]; in all cases there was no evidence of traumatic injury of the duct. In our case, internal drainage of the pancreatic pseu- 


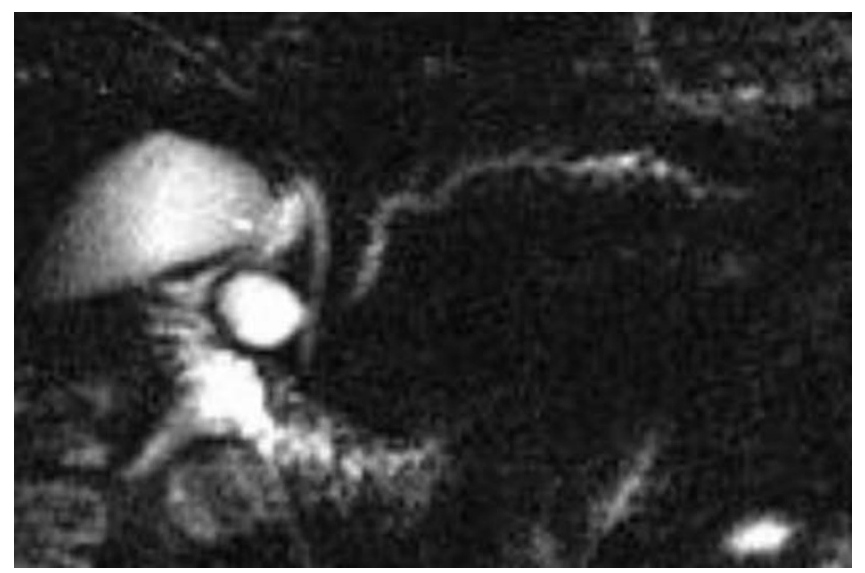

Figure 4

Title: Projectional single shot turbo spin echo MRCP A dilated and tortuous pancreatic duct with associated beading of side branches in the body and tail of the pancreas is depicted, along with a short stricture of the duct in the pancreatic neck. The normal appearing common bile duct and the main pancreatic duct were shown ending at different parts of the duodenum after crossing over each other at the head of the pancreas. A cyst is demonstrated in the way of the dorsal pancreatic duct.

docyst was beneficial and resulted in symptoms remission.

\section{Discussion}

Pancreas divisum (PD) is not an uncommon congenital anatomic variant that results from failure of the ventral and dorsal ductal systems to fuse during the $6^{\text {th }}$ to $8^{\text {th }}$ week of embryological development. The main portion of the pancreas is drained by the dorsal pancreatic duct through the accessory papilla and only the posterior-inferior part and the uncinate process of pancreatic head are drained by a small and short ventral duct that joins the common bile duct in the ampulla of Vater [2]. Drainage of most of the pancreatic secretions through the accessory papilla, that is less wide than the main one, may result in high intraductal pressure in the duct of Santorini. This "functional" obstruction of the dorsal duct orifice has been assumed as a cause of acute pancreatitis $[1,8,6]$. The prevalence of $\mathrm{PD}$ has been reported from $0,8 \%$ to $7,5 \%$ on ERCP series [1] and it is found in $5-10 \%$ of autopsies [2]. The diagnosis of PD is based on ERCP findings, when a short isolated ventral duct is depicted, as in our case, or when two separate pancreatic ducts, that do not communicate to each other, are identified [1]. MRCP is considered an excellent technique in the diagnosis of PD by demonstrating the crossing of the distal common bile duct with the dorsal pancreatic duct and by revealing sep- arate drains for the main pancreatic and common bile ducts $[4,7]$. PD has been associated with episodes of acute recurrent pancreatitis and relapsing abdominal pain $[2,13,16]$. The relationship of PD with chronic pancreatitis has not been fully illuminated yet, although some reports- based mostly on clinical, laboratory and ERCP data- suggested that this congenital variant, may have a role in the pathogenesis of chronic pancreatitis [1,13-15]. Pancreatitis due to blunt abdominal trauma in patients with PD has been previously described on ERCP in only three cases, to the best of our knowledge $[16,17]$. Blunt abdominal trauma is considered to be the cause of one fifth of all cases of traumatic pancreatitis and it may result in contusion, parenchymal fracture, or ductal disruption [17]. Pancreatic trauma may lead to pseudocyst formation, abscess or pancreatic fistula formation [18]. Pancreatic pseudocyst may also be developed after an acute exacerbation of chronic pancreatitis [19]. It is unclear if the cyst is related to such an exacerbation of chronic pancreatitis in our patient. But we consider that the cystic lesion might be secondary to the blunt trauma, as a CT scan that was performed by that time, showed a peripancreatic hematoma at the pancreatic head.

Ductal injury is usually followed by a more severe clinical course in the posttraumatic period than in our case. As opposed to the duct of Santorini which was injured, the duct of Wirsung was intact in our patient; this may account for the absence of atrophic changes in the pancreatic head and the relatively mild clinical course. MRCP showed morphological alterations in the dorsal pancreas, consistent with chronic pancreatitis and the cross-sectional T1 and T2-weighted images demonstrated atrophy of the pancreatic body and tail. ERCP failed to depict the dorsal duct probably because its stenotic orifice.

\section{Conclusions}

Pancreas divisum may interfere with the clinical course, the post-traumatic changes and the sequelae of blunt trau$\mathrm{ma}$ in the pancreas. MRCP is able to diagnose pancreas divisum and demonstrate changes of chronic pancreatitis. Furthermore, due to its non-invasive nature, it can replace diagnostic ERCP in evaluation of patients with chronic abdominal pain and hyperamylasemia after blunt abdominal trauma and may help in designing endoscopic intervention.

\section{List of abbreviations}

PD: Pancreas Divisum

ERCP: Endoscopic Retrograde Cholangiopancreatography

MRI: Magnetic Resonance Imaging

MRCP: Magnetic Resonance Cholangiopancreatography 


\section{Acknowledgements}

Written consent was obtained from the patient or their relative for publication of the patient's details.

\section{References}

I. Eisendrath P, Delhaye M, Matos C, Baize M, Cremer M and Deviere J Prevalence and clinical evolution of isolated ventral pancreatitis in alcoholic pancreatitis. Gastrointest Endosc 2000, 5 I ( I ):4550

2. Morgan DE, Logan K, Baron TH, Koehler RE and Smith JK Pancreas divisum: implications for diagnostic and therapeutic pancreatography. AJR Am J Roentgenol I999, I73(I):193-8

3. Manfredi R, Costamagna G, Brizi MG, Maresca G, Vecchioli A, Colagrande $C$ and Marano $P$ Severe chronic pancreatitis versus suspected pancreatic disease: dynamic cholangiopancreatography after secretin stimulation. Radiology 2000, 2 l 4(3):849-55

4. Bret PM, Reinhold C, Taourel P, Guibaud L, Atri M and Barkun AN Pancreas divisum: evaluation with MR cholangiopancreatography. Radiology 1996, I99(I):99-103

5. Soto JA, Barish MA, Kent Yucel E, Clarke P, Siegenberg D, Chuttani $R$ and Ferrucci JT Pancreatic duct: MR Cholangiopancreatography with a three-dimensional fast spin-echo technique. $R a$ diology 1995, 196:459-464

6. Sanada Y, Yoshizawa Y, Chiba M, Nemoto H, Midorikawa T and Kumada $\mathrm{K}$ Ventral pancreatitis in a patient with pancreas divisum. J Pediatr Surg 1999, 30(5):665-667

7. Nicaise N, Pellet O, Metens Th, Deviere J, Braude Ph, Struyven J and Matos C Magnetic resonance cholangiopancreatography: interest of IV secretin administration in the evaluation of pancreatic ducts. Eur Radiol 1998, 8:16-22

8. Varshney S and Johnson CD Pancreas divisum. Int J Pancreatol I999, 25(2): I35-4I

9. Hatano S, Kondoh S, Akiyama T and Okita K Evaluation of MRCP compared to ERCP in the diagnosis of biliary and pancreatic duct. Nippon Rinsho 1998, 56( I I):2874-9

10. Dhar A, Goenka MK, Kochhar R, Nagi B, Bhasin DK and Singh K Pancreas divisum: five years' experience in a teaching hospital. Indian J Gastroenterol 1996, I 5(I):7-9

II. Gregg JA Pancreas divisum : its association with pancreatitis. Am J Surg 1977, I 34:539-43

12. Delhaye $M$ and Cremer $M$ Clinical significance of pancreas divisum. Acta Gastroenterol Belg 1992, 55(3):306-I3

13. Bousquet R, Olivier A, evrain B, Coffin JC and Charleux $\mathrm{H}$ Chronic pancreatitis and pancreas divisum. A propos of 3 cases treated surgically. Am J Surg 1983, I 45(5):582-4

14. Marshall JB and Eckhauser ML Pancreas divisum. A cause of chronic relapsing pancreatitis Dig Dis Sci 1985, 30(6):582-7

I5. Wind P, Berger A, Chevallier JM, Frileux P and Cugnene PH Pancreas divisum, chronic pancreatitis and diabetes mellitus. Improvement by pancreaticojejunostomy. Ann Chir 1992, 46(7):625-9

16. Cobb BW, Meyer KK and Cotton PB Recurrent pseudocysts and pancreatitis after trauma: a complication of pancreas divisum. Surgery 1985, 97(5):626-9

17. Portis M, Meyers P, McDonald JC and Gholson CF Traumatic pancreatitis in a patient with pancreas divisum: Clinical and radiographic features. Abdom Imaging 1994, I 9(2): I62-4

18. Silen W and Steer ML Pancreas. In: Principals of surgery (Edited by: Schwartz SI, Shires GT, Spencer MD) New York: McGraw-Hill I 989, I4241426

19. Grace PA and Williamson RC Modern management of pancreatic pseudocysts. Br J Surg 1993, 80:573-58I

\section{Pre-publication history}

The pre-publication history for this paper can be accessed here:

\section{http://www.biomedcentral.com/1471-230X/3/4/prepub}

Publish with Biomed Central and every scientist can read your work free of charge

"BioMed Central will be the most significant development for disseminating the results of biomedical research in our lifetime. "

Sir Paul Nurse, Cancer Research UK

Your research papers will be:

- available free of charge to the entire biomedical community

- peer reviewed and published immediately upon acceptance

- cited in PubMed and archived on PubMed Central

- yours - you keep the copyright

Submit your manuscript here:

http://www.biomedcentral.com/info/publishing_adv.asp
BioMedcentral 